\title{
Genetic and Molecular Mapping of Stripe Rust Resistance Gene in Wheat-Psathyrostachys huashanica Translocation Line H9020-1-6-8-3
}

\author{
Qiang Li, Jing Huang, Lu Hou, Pei Liu, Jinxue Jing, Baotong Wang, and Zhensheng Kang, State Key Laboratory of Crop Stress \\ Biology for Arid Areas/College of Plant Protection, Northwest A\&F University, Yangling 712100, China
}

\begin{abstract}
Li, Q., Huang, J., Hou, L., Liu, P., Jing, J., Wang, B., and Kang, Z. 2012. Genetic and molecular mapping of stripe rust resistance gene in wheatPsathyrostachys huashanica translocation line H9020-1-6-8-3. Plant Dis. 96:1482-1487.

Stripe rust, caused by Puccinia striiformis f. sp. tritici, is one of the most important diseases of wheat worldwide. The best strategy to control stripe rust is to grow resistant cultivars, but only a few effective genes are available. The wheat accession H9020-1-6-8-3 is a translocation line previously developed from interspecific hybridization between wheat genotype 7182 and Psathyrostachys huashanica, and is resistant to most Chinese Puccinia striiformis f. sp. tritici races. To identify the resistance genes in the translocation line, H9020-1-6-8-3 was crossed with susceptible genotype Mingxian 169, and seedlings of parents and $\mathrm{F}_{1}, \mathrm{~F}_{2}$, and $\mathrm{F}_{3}$ progenies were tested with prevalent Chinese $P$. striiformis $\mathrm{f}$. sp. tritici races CYR32 and CYR33 under controlled greenhouse conditions. The genetic results indicated that two single dominant genes in H9020-1-6-8-3 confer resistance to CYR32 and

CYR33, respectively. The gene for resistance to CYR33 was temporarily designated as $\mathrm{YrH}$ 9020. Six simple-sequence repeat markers were used to map the resistance gene to the short arm of wheat chromosome $2 \mathrm{D}$, using $329 \mathrm{~F}_{2}$ plants tested with CYR33 in the greenhouse. The genetic distances of the two closest flanking markers, Xgwm261 and Xgwm455, were 4.4 and 5.8 centimorgans, respectively. Disease assessments and polymorphic tests of the flanking markers among the Psathyrostachys huashanica line and wheat lines 7182, H9020-1-6-83 , and Mingxian169 suggested that the resistance gene $\mathrm{YrH} 9020$ in H9020-1-6-8-3 was originally from $P$. huashanica. The exotic stripe rust resistance gene and linked molecular markers should be useful for pyramiding with other genes to develop wheat cultivars with high-level and durable resistance to stripe rust.
\end{abstract}

Wheat stripe rust, also known as yellow rust and caused by $P u c$ cinia striiformis f. sp. tritici Erikss., is one of the most devastating diseases that plagues wheat (Triticum aestivum) production globally, especially in China $(5,6,20,31)$. China has the largest stripe rust epidemiologic region in the world in terms of wheat area affected by the disease, which is particularly destructive to autumnsown wheat in the northwest and southwest of the country $(20,32,34)$. Fifteen nationwide stripe rust epidemics have been recorded since 1950, and estimated losses of $6.0,3.2,1.8$, and 1.3 million tons of wheat occurred in 1950, 1964, 1990, and 2002, respectively $(20,34)$.

The most effective and economical approach to controlling the disease is growing resistant wheat cultivars $(5,20,21)$. To date, more than 40 stripe rust resistance genes with official $\mathrm{Yr}$ designations have been reported in wheat, and many genes and quantitative trait loci (QTLs) have been temporarily named $(5,9,12$, $17,18,26,27)$. However, the majority of these genes are racespecific, and new $P$. striiformis f. sp. tritici races usually overcome the resistances used in cultivars within a few years of commercial production $(8,20)$. Gene pyramiding, gene deployment, and multiline cultivar strategies are considered useful for protecting and prolonging the resistance of cultivars. The effective use of such strategies depends greatly on the availability of a range of resistance genes. However, only a few genes are available conferring effective all-stage resistance against the current populations of the pathogen worldwide. Therefore, it is urgent to identify new stripe rust resistance genes from various origins for diversifying resistance and pyramiding genes for different types of resistance in order to achieve high-level and durable resistance for sustainable control of stripe rust.

Corresponding authors: B. Wang, E-mail: baotongwang@126.com and Z. Kang, E-mail: kangzs@nwsuaf.edu.cn

Accepted for publication 5 March 2012.

http://dx.doi.org/10.1094/PDIS-03-11-0204-RE

(C) 2012 The American Phytopathological Society
In addition to wheat landraces, wild wheat relatives are also important resources for stripe rust resistance in wheat breeding. Thus far, among the officially designated $\operatorname{Yr}$ genes, $\operatorname{Yr} 5, \operatorname{Yr} 8, \operatorname{Yr} 9, \operatorname{Yr} 15$, Yr17, Yr19, Yr28, Yr35, Yr36, Yr37, Yr38, Yr40, and Yr42 were identified from wild wheat relatives. Among these, $\operatorname{Yr} 5$ and $Y r 15$ are still resistant to most prevalent Chinese $P$. striiformis $\mathrm{f}$. $\mathrm{sp}$. tritici races (38).

Psathyrostachys huashanica Keng. $(2 \mathrm{n}=2 \mathrm{x}=14$, NsNs $)$, a perennial cross-pollinating plant and a wild relative of common wheat, has been found only on Huashan Mountain in Shaanxi province, China. Therefore, it has been listed as an endangered and protected wild species in China. $P$. huashanica is characterized by early maturity and possesses many valuable traits such as winter hardiness, resistance to sterility drought tolerance, and broad-spectrum disease resistance. Through interspecific hybridization between wheat line ' 7182 ' and $P$. huashanica, embryo rescue technology, and subsequent extensive backcrossing with this wheat parent line, Chen et al. (4) have developed several translocation wheat lines, which greatly facilitates the utilization of $P$. huashanica in wheat breeding programs.

A preliminary study on inheritance of the resistance to stripe rust in $P$. huashanica accession 0503383 and some translocation lines indicated that $P$. huashanica has valuable disease resistance genes, which can be highly expressed in a wheat background (13). From translocation line, H9020-17-5, Cao et al. (3) identified a single dominant gene, YrHua, which confers resistance to Puccinia striiformis f. sp. tritici race CYR 31, and located the gene on wheat chromosome 6AL.

The current study focused on identifying the gene or genes conferring all-stage stripe rust resistance in another wheatPsathyrostachys huashanica translocation line, H9020-1-6-8-3, which is resistant to most Chinese Puccinia striiformis f. sp. tritici races in both the seedling and adult-plant stage. Its resistance spectrum was different from H9020-17-5 in our preliminary tests using genetic analysis and molecular mapping.

\section{Materials and Methods}

Plant materials. H9020-1-6-8-3 is a wheat-Psathyrostachys huashanica translocation line which derived from the hybridization 
between donor parent $P$. huashanica accession 0503383 and receptor parent 7182 wheat. 'Mingxian 169' is a winter wheat cultivar that is susceptible to all Chinese Puccinia striiformis f. sp. tritici races identified thus far. To study the genetics of and develop molecular markers for its stripe rust resistance, H9020-1-6-8-3 was crossed with Mingxian 169, using Mingxian 169 as the female parent. $F_{1}, F_{2}$, and $F_{3}$ generations and parents were used in seedling tests in the greenhouse for identifying the genes for all-stage resistance in H9020-1-6-8-3.

The Psathyrostachys huashanica accession 0503383 and wheat 7182 were also tested in the greenhouse with 14 Puccinia striiformis f. sp. tritici races to identify the resistance spectrum of Psathyrostachys huashanica and deduce the origin of the stripe rust resistance gene in H9020-1-6-8-3. Also, wheat- $P$. huashanica translocation line H9020-17-5 was tested with these Puccinia striiformis $\mathrm{f}$. sp. tritici races to distinguish the stripe rust resistance gene in H9020-17-5 from that in H9020-1-6-8-3.

Pathogen isolates and disease assessment. Seedling tests were conducted under controlled greenhouse conditions as described by $\mathrm{Li}$ and Zeng (20). In total, $14 P$. striiformis $\mathrm{f}$. sp. tritici races (CYR10, CYR21, CYR22, CYR23, CYR25, CYR27, CYR29, CYR29-mut3, CYR30, CYR31, CYR32, CYR33, Su11-4, and Su11-11), with various virulence gene combinations, were chosen to test seedlings of Psathyrostachys huashanica accession 0503383, wheat 7182 and Mingxian 169, and wheat-P. huashanica translocation lines H9020-1-6-8-3 and H9020-17-5. CYR32, which overcomes the resistance of most Chinese wheat cultivars and breeding lines, was the predominant race in China from 2001 to 2007 (34). CYR33 was the second most prevalent race after CYR32 from 2002 to 2007, and it has been the most prevalent race since 2008 (National Wheat Rust Research Group, unpublished observation). Thus, CYR32 and CYR33 were selected to test $\mathrm{F}_{1}$, $F_{2}$, and $F_{3}$ populations derived from Mingxian $169 \times$ H9020-1-6-83 , and the resistance gene to CYR33 in H9020-1-6-8-3 was selected to construct a genetic linkage map.

Seed of the two parents and $F_{1}, F_{2}$, and $F_{3}$ progenies were grown in pots $10 \mathrm{~cm}$ in diameter. About 15 seeds for each parent, 3 seeds for the $F_{1}$ lines, 300 seeds for the $F_{2}$ lines, and 15 seeds for each of the $\mathrm{F}_{3}$ lines were planted, with about 15 seeds in each pot of the $\mathrm{F}_{2}$ and $\mathrm{F}_{3}$ progeny.

When the first leaves were fully expanded (about 10 days after planting), all seedlings were inoculated with fresh urediniospores of selected Puccinia striiformis f. sp. tritici isolates that were increased on susceptible wheat Mingxian 169, using the brushing method (20). After inoculation, the seedlings were placed in a dew chamber at $9^{\circ} \mathrm{C}$ and $100 \%$ relative humidity for $24 \mathrm{~h}$, then trans- ferred to a greenhouse maintained with $14 \mathrm{~h}$ of light and $10 \mathrm{~h}$ of darkness at 12 to $17^{\circ} \mathrm{C}$. Infection types (ITs) were scored 15 to 16 days after inoculation, when rust was fully developed on the susceptible check, Mingxian 169, based on the scale of 0,$0 ;, 0 ;{ }^{+}, 1$, $1^{+}, 2,2^{+}, 3^{-}, 3,3^{+}$, and $4(2,19)$. Plants with ITs of 0 to $2^{+}$were considered resistant and those with ITs of $3^{-}$to 4 susceptible $(19,22)$.

DNA extraction and bulk segregant analysis. Genomic DNA was isolated from leaves using the cetyltrimethyl ammonium brommide method $(30,37)$, dissolved in $1 \times$ Tris-EDTA buffer $(10$ $\mathrm{mM}$ Tris- $\mathrm{HCl}$ and $1 \mathrm{mM}$ EDTA, $\mathrm{pH} 8.0$ ), and stored at $-20^{\circ} \mathrm{C}$. DNA was quantified using the mini-gel method (25) and a spectrophotometer (NanoDrop ND-1000; Thermo Fisher Scientific Inc., Wilmington, DE). The DNA stock solution was adjusted to 30 $\mathrm{ng} / \mu \mathrm{l}$ with sterilized, deionized, and distilled water for use as the working solution for polymerase chain reaction (PCR).

The $\mathrm{F}_{2}$ plants inoculated with CYR33 were used to construct the mapping population. Aliquots of DNA from the 10 most resistant and the 10 most susceptible $\mathrm{F}_{2}$ plants were combined into resistant and susceptible bulks, respectively (29). The simple-sequence repeat (SSR) procedure was used to screen for potential markers linked to the resistance locus (14). Wheat SSR primers were synthesized by Shanghai Generay Biotech Co., Ltd, (Shanghai, China) according to the sequences published on the GrainGenes website (http://wheat.pw.usda.gov/GG2/index.shtml). In total, 355 SSR primer pairs covering all wheat chromosomes were screened on the parents and the bulks, among which were 36 SSR primer pairs located on chromosome 2DS and 34 SSR primer pairs located on chromosome 2DL, to further characterize the translocated line H9020-1-6-8-3 in detail. Primer pairs generating specific bands in both H9020-1-6-8-3 and the resistant bulks or Mingxian 169 and the susceptible bulks were used to genotype the $329 \mathrm{~F}_{2}$ individual plants.

PCR amplification, electrophoresis, and gel visualization. The PCR reactions were performed in a PTC-200 Thermo Cycler (BioRad Laboratories, Inc.). A $15-\mu$ reaction mixture consisted of $45 \mathrm{ng}$ of template DNA; $1.5 \mu \mathrm{l}$ of Mg-free 10× PCR buffer; 0.6 unit of Taq DNA polymerase (Mbi Fermentas Inc., Ontario, Canada); $5 \mathrm{mM}$ $\mathrm{MgCl}_{2} ; 0.25 \mathrm{mM}$ each of dCTP, dGTP, dTTP, and dATP; and 7.5 $\mu \mathrm{M}$ each primer. The PCR amplification conditions were as follows: after $4 \mathrm{~min}$ of denaturation at $94^{\circ} \mathrm{C}$, amplifications were programmed for 35 consecutive cycles, each consisting of $1 \mathrm{~min}$ at $94^{\circ} \mathrm{C}, 1 \mathrm{~min}$ at 50,55 , or $60^{\circ} \mathrm{C}$ (depending on the individual primers), and $1 \mathrm{~min}$ at $72^{\circ} \mathrm{C}$; and then a 10 -min extension step at $72^{\circ} \mathrm{C}$.

After amplification, $6 \mu \mathrm{l}$ of formamide loading buffer $(98 \%$ formamide, $10 \mathrm{mM}$ EDTA [pH 8.0], 0.5\% [wt/vol] xylene cyanol,

Table 1. Infection types on accessions of Psathyrostachys huashanica, wheat, and wheat-P. huashanica translocation lines tested with races of Puccinia striiformis $\mathrm{f}$. sp. tritici as seedlings

\begin{tabular}{|c|c|c|c|c|c|c|}
\hline \multirow[b]{2}{*}{ Races } & \multirow[b]{2}{*}{ Virulence formula $^{\mathbf{b}}$} & \multicolumn{5}{|c|}{ Infection types $^{\mathrm{a}}$} \\
\hline & & P. huas & 7182 & H9020-1-6-8-3 & H9020-17-5 & Mingxian 169 \\
\hline CYR10 & 2 & 0 & 3 & 0 & $0-3$ & 3 \\
\hline CYR21 & $1,2,3,4,6,7,8,9,10,11$ & 0 & 4 & 3 & 0 & 3 \\
\hline CYR22 & $1,2,3,4,6,7,8,9,10,11,13$ & 0 & $3-4$ & $0-3$ & 0 & 4 \\
\hline CYR23 & $1,2,3,4,6,7,8,9,11$ & 0 & 4 & 3 & 0 & $3-4$ \\
\hline CYR25 & $1,2,3,4,5,6,7,8,9,11$ & 0 & 3 & 0 & 0 & 3 \\
\hline CYR27 & $1,2,3,4,5,6,7,8,9,10,11,13$ & 0 & 3 & 3 & 0 & 4 \\
\hline CYR29 & $1,2,3,4,5,6,7,8,9,11,12,16$ & 0 & 3 & $0-0$ & 0 & $3^{+}-4$ \\
\hline CYR29-mut3 & $1,2,3,4,8,11$ & 0 & 3 & $0-0$ & 0 & $3-4$ \\
\hline CYR30 & $1,2,3,4,5,6,7,8,9,11,12,16,17$ & 0 & 4 & $0 ;-1$ & 0 & 4 \\
\hline CYR31 & $1,2,3,4,5,6,7,8,9,11,12,14,16,17$ & 0 & 4 & $0 ;^{+}$ & $0 ;-1$ & 4 \\
\hline CYR32 & $1,2,3,4,5,6,7,8,9,10,11,12,13,14,16,17$ & 0 & 4 & $0 ;-2$ & $0-0$ & 4 \\
\hline CYR33 & $1,2,3,4,5,6,7,8,9,10,11,12,13,14,16$ & 0 & 4 & $0 ;-2$ & $0-0$ & $3^{+}-4$ \\
\hline Su11-4 & $1,2,3,4,6,7,8,9,10,11,13,14,16$ & 0 & $3^{+}-4$ & 0 & 0 & 4 \\
\hline Su11-11 & $1,2,3,4,6,7,8,9,10,11,13,14$ & 0 & 4 & $0 ;{ }^{+}-1$ & 0 & 4 \\
\hline
\end{tabular}

a $P$. huas indicates Psathyrostachys huashanica accession 0503383, 7182 and Mingxian 169 are common wheat cultivars, and H9020-1-6-8-3 and H9020-175 are translocation lines derived from the hybridization between $P$. huashanica accession 0503383 and 7182 .

${ }^{\text {b }}$ Chinese differential genotypes: 1, Trigo Eureka; 2, Fulhard; 3, Lutescens 128; 4, Mentana; 5, Virgilio; 6, Abbondanza; 7, Early premium; 8, Funo; 9 , Danish 1; 10, Jubilejina 2; 11, Fengchan 3; 12, Lovirn13; 13, Kangyin 655; 14, Shuiyuan 11; 15, Zhong 4; 16, Lovirn 10; 17, Hybrid 46; 18, Triticum spelta ablum; 19, Guinong 22. 
and $0.5 \%$ [wt/vol] bromophenol blue] was added to the PCR products. About 4 to $5 \mu \mathrm{l}$ of the PCR product and loading buffer mixture for each sample was loaded for electrophoresis in a $6 \%$ polyacrylamide gel as previously described (7). After electrophoresis, the gel was silver-stained for visualization (7).

Data analysis. To evaluate the goodness of fit of observed and expected segregation ratios in $\mathrm{F}_{2}$ and $\mathrm{F}_{3}$ progenies to establish the number of stripe rust resistance genes and mode of inheritance, $\chi^{2}$ tests were used. The "Chitest" procedure in the data analysis of Microsoft Office 2003 was used to calculate $\chi^{2}$ and $P$ values of $\chi^{2}$ tests. Linkage analysis was conducted with Mapmaker 3.0b (16). Map distance in centimorgans was calculated according to the Kosambi mapping function (15), and a log of the likelihood ratio score of 3.0 was used as the threshold for a declaration of linkage. The Mapdraw 2.1 program was used to draw the linkage map.

\section{Results}

Origin of stripe-rust resistance in H9020-1-6-8-3. Seedling IT data from tests with the $14 P$. striiformis $\mathrm{f}$. sp. tritici races on H9020-1-6-8-3, Mingxian169 (as a control), and the direct parent lines of H9020-1-6-8-3 (Psathyrostachys huashanica accession 0503383 and wheat line 7182) are shown in Table 1. H9020-1-6-83 was resistant (IT 0 ; to 2) to 10 of the tested races (CYR10, CYR25, CYR29, CYR29-mut3, CYR30, CYR31, CYR32, CYR33, Su11-4, and Su11-11); susceptible (IT 3) to P. striiformis f. sp. tritici races CYR21, CYR23, and CYR27; and showed a variable IT to CYR22 (IT 0 to 3). By contrast, Mingxian169 was susceptible (IT 3 to 4 ) to all tested races. As for the parents of H9020-1-6-8-3, only P. huashanica accession 0503383 was highly resistant (IT 0;) to all tested races, similar to the reaction of H9020-1-6-8-3 to 10 of the races. In contrast, the other parent, wheat line 7182, was susceptible (IT 3 to 4 ) to all tested races. This result suggested that the stripe rust resistance of H9020-1-6-8-3 to these 10 races is controlled by an alien resistance gene originating from $P$. huashanica accession 0503383.

Inheritance of stripe rust resistance in $\mathbf{H 9 0 2 0 - 1 - 6 - 8 - 3}$. The reactions of the $F_{1}, F_{2}$, and $F_{3}$ generations from the cross Mingxian $169 \times$ H9020-1-6-8-3 to races CYR32 and CYR33 are shown in Table 2 .

When tested with CYR32, $F_{1}$ plants responded with IT 0;, indicating dominance of resistance. In all, $227 \mathrm{~F}_{2}$ plants segregated into 168 resistant and 59 susceptible, fitting a 3:1 resistant/susceptible ratio $\left(\chi^{2}=0.12, P=0.73\right)$, suggesting that a single dominant gene confers resistance to CYR32. The $\mathrm{F}_{3}$ generation had 55 homozygous resistant, 109 segregating, and 41 homozygous susceptible lines, which fit a 1:2:1 (resistant/segregating/susceptible) ratio $\left(\chi^{2}=2.74\right.$, $P=0.25$ ), confirming that a single dominant gene is involved in stripe rust resistance to CYR32.

All three $F_{1}$ plants were resistant to CYR33. Of the $329 F_{2}$ plants, 254 plants were resistant and 75 susceptible, fitting a 3:1 resistant/susceptible ratio $\left(\chi^{2}=0.85, P=0.36\right)$, indicating that a single dominant gene is involved in resistance to CYR33. Among $235 \mathrm{~F}_{3}$ families, 59 were homozygous resistant, 127 segregating, and 49 homozygous susceptible lines, showing a 1:2:1 (resistant/segregating/susceptible) ratio $\left(\chi^{2}=2.38, P=0.30\right)$. This further confirmed that a single dominant gene is associated with stripe rust resistance to CYR33, and the gene was temporarily designated as $\mathrm{YrH} 902 \mathrm{O}$.

Molecular mapping of the stripe rust resistance gene. Of the 355 SSR markers employed in this study, 116 markers $(32.4 \%)$ showed clear polymorphisms between the two parents. Among these 116 markers, 16 were located on wheat chromosome 2DS and 10 were located on chromosome 2DL. All 116 markers were used for further investigation of resistant and susceptible DNA bulks. Of the 116 markers, only six SSR loci, (Xgwm102, $X g w m 455, X g w m 261, X w m c 503, X c f d 53$, and Xgpw332), all located on wheat chromosome 2DS, produced strong and repeatable bands that were polymorphic between the resistant and susceptible bulks as well as their parents. This indicated that $\mathrm{YrH} 9020$ was located on chromosome 2DS. Subsequent linkage analysis, based on the phenotypic and genotypic data on the six polymorphic markers in the $F_{2}$ population, indicated that the resistance gene $\mathrm{YrH} 9020$ was linked to the six SSR loci, with genetic distances of 4.4 to 14.6 centimorgans (cM) (Figs. 1 and 2). The two closest flanking SSR loci were Xgwm261 and Xgwm455, with genetic distances of 4.4 and $5.8 \mathrm{cM}$, respectively. Among the six polymorphic markers, Xgwm102, Xgwm455, and Xcfd53 were co-dominant, and Xgwm261, Xwmc503, and Xgpw332 were dominant.

The linkage analysis based on the data from $\mathrm{F}_{3}$ families genotyped with the most closely linked markers Xgwm455 and Xgwm261 confirmed the $\mathrm{F}_{2}$ results (Table 3). For the $235 \mathrm{~F}_{3}$ families, 55 of the 59 homozygous resistant genotypes carried the same allele as that of resistant parent H9020-1-6-8-3 at the SSR locus $X g w m 455$, and four were heterozygous. For the 127 segregating $\mathrm{F}_{3}$ families, 112 were detected to have heterozygous genotypes; 4 had the same allele as H9020-1-6-8-3, and 11 the same allele as that of susceptible parent Mingxian 169. For the 49 homozygous susceptible genotypes, 39 carried the same allele as Mingxian 169, whereas 3 had the same allele as H9020-1-6-8-3 and 7 were heterozygous.

To further confirm the origin of the stripe rust resistance gene in H9020-1-6-8-3, four polymorphic SSR markers (Xgwm261, Xgwm455, Xgwm102, and Xcfd53) were used to test H9020-1-6-83, Mingxian 169, P. huashanica accession 0503383, and 7182 . H9020-1-6-8-3 and $P$. huashanica produced the same polymorphic bands, whereas Mingxian 169 and 7182 had the same sized band, which further confirmed that the stripe rust resistance gene YrH9O2O in H9020-1-6-8-3 originated from P. huashanica accession 0503383.

\section{Discussion}

Because of the high variability of Puccinia striiformis f. sp. tritici races and a limited number of race-specific resistance genes

Table 2. Observed numbers, expected ratios, and $\chi^{2}$ tests on plants or lines of parents and $\mathrm{F}_{1}, \mathrm{~F}_{2}$, and $\mathrm{F}_{3}$ generations from the cross Mingxian169 $\times \mathrm{H} 9020-1$ 6-8-3 tested with most prevalent Chinese Puccinia striiformis f. sp. tritici races CYR32 and CYR33

\begin{tabular}{|c|c|c|c|c|c|c|c|}
\hline \multirow[b]{2}{*}{ Test race } & \multirow[b]{2}{*}{ Parents or population ${ }^{b}$} & \multicolumn{3}{|c|}{ Observed number of plants or lines ${ }^{a}$} & \multirow[b]{2}{*}{ Expected ratio } & \multirow[b]{2}{*}{$\chi^{2}$} & \multirow[b]{2}{*}{$P$ value } \\
\hline & & Res. & Seg. & Susc. & & & \\
\hline \multirow[t]{5}{*}{ CYR32 } & H9020-1-6-8-3 & 14 & - & 0 & $\ldots$ & $\ldots$ & $\ldots$ \\
\hline & Mingxian169 & 0 & - & 13 & $\ldots$ & $\ldots$ & $\ldots$ \\
\hline & $\mathrm{F}_{1}$ & 3 & - & 0 & $\ldots$ & $\ldots$ & $\ldots$ \\
\hline & $\mathrm{F}_{2}$ & 168 & - & 59 & $3: 1$ & 0.12 & 0.73 \\
\hline & $\mathrm{F}_{3}$ & 55 & 109 & 41 & $1: 2: 1$ & 2.74 & 0.25 \\
\hline \multirow[t]{5}{*}{ CYR33 } & H9020-1-6-8-3 & 15 & - & 0 & $\ldots$ & $\ldots$ & $\ldots$ \\
\hline & Mingxian169 & 0 & - & 12 & $\ldots$ & $\ldots$ & $\ldots$ \\
\hline & $\mathrm{F}_{1}$ & 3 & - & 0 & $\ldots$ & $\ldots$ & $\ldots$ \\
\hline & $\mathrm{F}_{2}$ & 254 & - & 75 & $3: 1$ & 0.85 & 0.36 \\
\hline & $\mathrm{F}_{3}$ & 59 & 127 & 49 & $1: 2: 1$ & 2.38 & 0.30 \\
\hline
\end{tabular}

${ }^{\mathrm{a}}$ Res. $=$ resistant, Seg. $=$ segregating, and Susc. $=$ susceptible.

${ }^{\mathrm{b}}$ H9020-1-6-8-3 = wheat-Psathyrostachys huashanica translocation line; Mingxian169 $=$ winter wheat cultivar susceptible to all Chinese Puccinia striiformis $\mathrm{f}$. sp. tritici races. 
used in breeding programs, resistances in wheat cultivars have been continually overcome by emerging races, which has resulted in seven to eight large-scale replacements of cultivars since the 1950s in China (20,34). Furthermore, with the appearance and development of new virulent races CYR32 and CYR33, most commercial and candidate varieties lost resistance in recent years. Thus, extensive screening of potentially new sources of resistance, including those from wild wheat relatives, is urgently needed for wheat resistance breeding.

Indeed, utilization of exotic genes has made substantial contributions to wheat resistance improvement in China. Since the early 1970 s, wheat cultivars with the 1B/1R translocation carrying $\operatorname{Yr} 9$, primarily derived from Secale cereale and carrier cultivars 'Lovrin 13', 'Predgornaia 2', 'Kavkaz', 'Neuzucht', and their derivatives, have been widely used in wheat breeding programs in China (11). About $80 \%$ of Chinese wheat varieties contained $\mathrm{Yr} 9$ and succumbed to destructive stripe rust epidemics in 1990 and 2002 $(11,19,34,36)$. In addition, 'Zhong 4' and 'Guinong 22', the Chinese differential hosts of $P$. striiformis $\mathrm{f}$. sp. tritici, show high-level resistance to all the known $P$. striiformis $\mathrm{f}$. sp. tritici races and pathotypes and have also been utilized in wheat resistance breeding $(10,35)$. The stripe rust resistance gene in Zhong 4 originated from Thinopyrum intermedium (33), and that in Guinong 22 was introgressed from a derivative of Haynaldia villosa and Triticum durum (39).

The wheat-Psathyrostachys huashanica translocation line H9020-1-6-8-3 used in this study was resistant to most prevalent Chinese Puccinia striiformis f. sp. tritici races in the seedling stage. The results of the genetic analysis indicated that the resistance to CYR32 and CYR33 in H9020-1-6-8-3 was controlled by two single dominant genes, one for CYR32 and one for CYR33, and the gene conferring resistance to CYR33 was located on chromosome 2DS by six SSR polymorphic markers. According to the genotypic data from the six markers in the $\mathrm{F}_{2}$ and $\mathrm{F}_{3}$ populations, some recombinant plants occurred in the $F_{2}$ and $F_{3}$ populations, and the result was similar with H9020-17-5 (3). When testing polymorphic amplified fragment length polymorphism (AFLP) markers on the $132 \mathrm{~F}_{2}$ plants derived from the cross of wheat-Leymus mollis (Trin.) Hara translocation line 93784 and the susceptible wheat 'WL1', Zhou et al. (40) also found some recombinant plants. Research on the phenomenon of recombination within a translocated piece of an alien chromosome is underway.

To date, stripe rust resistance genes (QTLs) Yr16, YrKat, QYr.inra-2DS, and QYr.caas-2DS have been located on the short arm of chromosome 2D $(1,23,24,28)$. Yrl6 originally derived from T. aestivum and is a non-race-specific, adult-plant resistance gene
(28). YrKat derived from 'Katepwa' and is a temperature-sensitive stripe rust resistance gene (1). Both QYr.inra-2DS and QYr.caas$2 D S$ are QTLs for reduced stripe rust severity in the adult-plant stage that derived from French bread wheat 'Camp Rémy' and Italian common wheat 'Libellula', respectively $(23,24)$. However, YrH9O20 in H9020-1-6-8-3 derived from Psathyrostachys huashanica and is a gene for race-specific, all-stage resistance. Therefore, $\mathrm{YrH} 9020$ is unlikely to be identical to $\mathrm{Yr} 16, \mathrm{YrKat}$, QYr.inra-2DS, or QYr.caas-2DS. YrHua derived from another wheat $-P$. huashanica translocation line, H9020-17-5, and was located on wheat chromosome 6AL by SSR marker Xgwm169 (3). Polymorphic tests indicated that Xgwm169 was not present in H9020-1-6-8-3, and the flanking markers for $\mathrm{YrH} 9020, \mathrm{Xgwm} 261$, and Xgwm455 were also absent in H9020-17-5. Cao et al. (3) converted AFLP marker PM14 (301) into an STS marker linked to

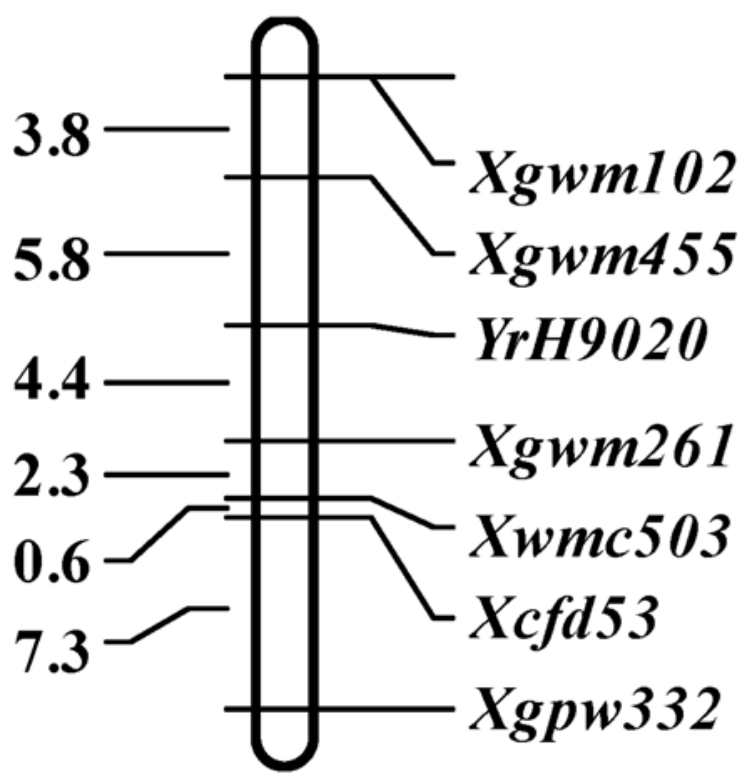

Fig. 2. Linkage map of stripe rust resistance gene $\mathrm{YrH} 9020$ in wheatPsathyrostachys huashanica translocation line H9020-1-6-8-3 and six polymorphic simple-sequence repeat markers on wheat chromosome 2DS based on $329 \mathrm{~F}_{2}$ plants from cross of H9020-1-6-8-3 with susceptible wheat 'Mingxian 169', tested with most prevalent Chinese Puccinia striiformis f. sp. tritici race CYR33. Locus names are indicated on the right and genetic distances between loci in centimorgans on the left.
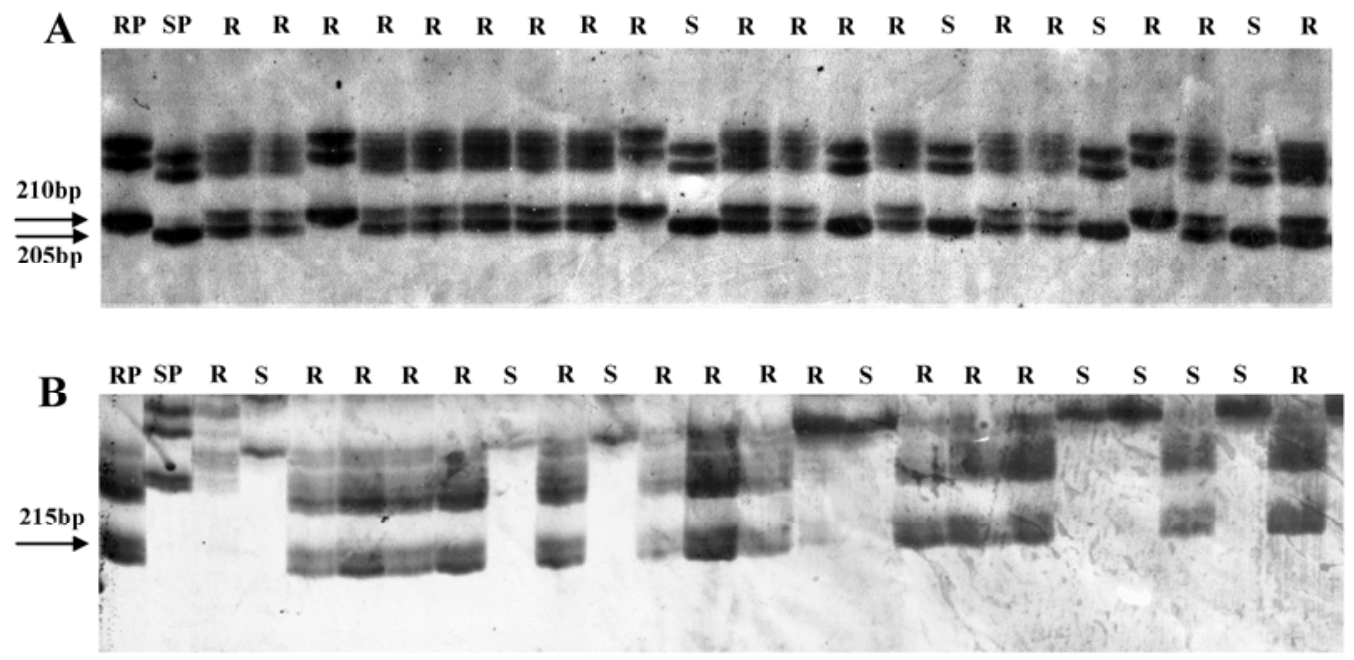

Fig. 1. Electrophoresis of polymerase chain reaction products amplified with simple-sequence repeat markers A, Xgwm102 and B, Xgpw332 in polyacrylamide gel. RP, resistant parent H9020-1-6-8-3 (wheat-Psathyrostachys huashanica translocation line); SP, susceptible parent, wheat 'Mingxian 169'; R, resistant $F_{2}$ individual plant; and S, susceptible $F_{2}$ individual plant from Mingxian $169 \times$ H9020-1-6-8-3 cross tested with most prevalent Chinese Puccinia striformis f. sp. tritici race CYR33. Arrow indicates the polymorphic band. 
Table 3. $F_{2}$ genotypes inferred from seedling reactions of $F_{3}$ families from cross Mingxian $169 \times$ H9020-1-6-8-3 tested with most prevalent Chinese Puccinia striiformis f. sp. tritici race CYR33 and the alleles of the H90201-6-8-3 resistance gene $\mathrm{YrH} 9020$ at the two closest flanking simplesequence repeat loci Xgwm 455 and Xgwm261

\begin{tabular}{lrrrr}
\hline & \multicolumn{3}{c}{ Allele $^{\mathbf{a}}$} & \\
\cline { 2 - 4 } Markers, genotypes $^{\mathbf{b}}$ & \multicolumn{1}{c}{$\mathbf{A}$} & $\mathbf{H}$ & B & Total \\
\hline Xgwm455 & 55 & 4 & 0 & \\
RR & 4 & 112 & 11 & 59 \\
Rr & 3 & 7 & 39 & 427 \\
rr & 62 & 123 & 50 & 235 \\
Total & & & & \\
Xgwm261 & 58 & - & 1 & 59 \\
RR & 116 & - & 11 & 127 \\
Rr & 9 & - & 40 & 49 \\
rr & 183 & - & 52 & 235 \\
Total & & & \\
\hline
\end{tabular}

a A, homozygous for H9020-1-6-8-3 (wheat-Psathyrostachys huashanica translocation line); $\mathrm{H}$, heterozygous; and B, homozygous for Mingxian 169 (winter wheat cultivar).

${ }^{b} \mathrm{RR}$, homozygous resistant; Rr, segregating; and rr, homozygous susceptible.

YrHua, and this STS marker was also absent in H9020-1-6-8-3. Furthermore, among 14 tested Puccinia striiformis f. sp. tritici races, H9020-1-6-8-3 was susceptible (IT 3) to CYR21, CYR23, and CYR27, and resistant-to-susceptible to CYR22 (IT 0 to 3). However, H9020-17-5 was resistant (IT 0 to 2 ) to all tested races, except for its resistant-to-susceptible reaction (IT 0 to 3) to CYR10 (Table 1). These results suggest that $\mathrm{YrH} 9020$ should be different from YrHua and might be a new gene.

Psathyrostachys huashanica is a wild grass species related to wheat but different from other alien species from which stripe rust resistance genes have been reported and used in wheat breeding programs. Its resistance genes have been translated into a series of translocation, substitution, and addition lines through interspecific crossing between $P$. huashanica and wheat genotype 7182, which greatly facilitates utilization of resistance genes from $P$. huashanica in wheat resistance breeding programs. Unfortunately, $P$. huashanica resistance has not been used in wheat breeding programs thus far because of the poor understanding of its genetic basis and lack of linked molecular markers. In the present study, six SSR markers were identified to be linked to the resistance gene YrH9020, with genetic distance of 4.4 to $14.6 \mathrm{cM}$. Such linked SSR markers should be useful for marker-assisted selection. In wheat breeding programs, use of molecular markers may greatly facilitate resistance gene pyramiding and deployment, and improve breeding efforts in achieving durable stripe rust resistance.

\section{Acknowledgments}

Q. Li and J. Huang are co-first authors. This research was supported by the National Natural Science Foundation of China (grant number 30771397), Special Fund for Agro-scientific Research in the Public Interest (grant number 200903035), the 111 Project from Education Ministry of China (grant number B07049), and the Scientific Research Foundation for Returning Overseas Chinese Scholars, Northwest A\&F University, Chinese Universities Scientific Fund (grant number QN2011009).

\section{Literature Cited}

1. Bariana, H. S., Hayden, M. J., Ahmed, N. U., Bell, J. A., Sharp, P. J., and McIntosh R.A. 2001. Mapping of durable adult plant and seedling resistances to stripe rust and stem rust diseases in wheat. Aust. J. Agric. Res. 52:1247-1255.

2. Bariana, H. S., and McIntosh, R. A. 1993. Cytogenetic studies in wheat XV. Location of rust resistance genes in VPM1 and their genetic linkage with other disease resistance genes in chromosome 2A. Genome 36:476-482.

3. Cao, Z. J., Deng, Z. Y., Wang, M. N., Wang, X. P., Jing, J. X., Zhang, X. Q., Shang, H. S., and Li, Z. Q. 2008. Inheritance and molecular mapping of an alien stripe-rust resistance gene from a wheat-Psathyrostachys huashanica translocation line. Plant Sci. 174:544-549.

4. Chen, S. Y., Zhang, A. J., and Fu, J. 1991. The hybridization between common wheat and Psathyrostachys huashanica. Acta Genet. Sin. 18:508-512.

5. Chen, X. M. 2005. Epidemiology and control of stripe rust on wheat. Can. J. Plant Pathol. 27:314-337.
6. Chen, X. M. 2007. Challenges and solutions for stripe rust control in the United States. Aust. J. Agric. Res. 58:648-655.

7. Chen, X. M., Line, R. F., and Leung, H. 1998. Genome scanning for resistance-gene analogs in rice, barley, and wheat by high-resolution electrophoresis. Theor. Appl. Genet. 97:345-355.

8. Chen, X. M., Ling, P., Wood, D. A., Moore, M. K., and Pahalawatta, V. 2003. Epidemiology and control of wheat stripe rust in the United States, 2003. Ann. Wheat Newsl. 50:274-276.

9. Cheng, P., and Chen, X. M. 2010. Molecular mapping of a gene for stripe rust resistance in spring wheat cultivar IDO377s. Theor. Appl. Genet. 121:195-204

10. Cheng, Y., Song, W., Liu, Z. Y., Xie, C. J., Ni, Z. F., Ru, P. H., Nie X. L., Yang, Z. M., and Sun, Q. X. 2006. Microsatellite markers for a yellow rust resistant gene in wheat cultivar Guinong 21. Acta Agron. Sin. 32:18671872.

11. He, Z. H., Rajaram, S., Xin, Z. Y., and Zhang, G. Z. 2001. A History of Wheat Breeding in China. CIMMYT, Mexico, D.F

12. Herrera, S. A., Lagudah, E. S., Julio H. E., Hayden, M. J., Bariana H. S., Singh, D., and Singh R. P. 2011. New slow-rusting leaf rust and stripe rust resistance genes $\operatorname{Lr67}$ and $\mathrm{Yr} 46$ in wheat are pleiotropic or closely linked. Theor. Appl. Genet. 122:239-249.

13. Jing, J. X., Fu, J., Yuan, H. X., Wang, M. N., Shang, H. S., and Li, Z. Q. 1999. A preliminary study on heredity of the resistance to stripe rust in three wild relatives of wheat. Acta Phytopathol. Sin. 29:147-150.

14. Karakousis, A., Barr, A. R., Chalmers, K. J., Ablett, G. A., Holton, T. A., Henry, R. J., Lim, P., and Langridge, P. 2003. Potential of SSR markers for plant breeding and variety identification in Australian barley germplasm. Aust. J. Agric. Res. 54:1197-1210.

15. Kosambi, D. D. 1944. The estimation of map distances from recombination values. Ann. Eugen. 12:172-175.

16. Lander, E. S., Green, P., Abrahamson, J., Barlow, A., Daly, M. J., Lincoln, S. E., and Newburg, I. 1987. MAPMAKER: An interactive computer package for constructing primary genetic linkage maps of experimental and natural populations. Genomics 1:174-181.

17. Li, G. Q., Li, Z. F., Yang, W. Y., Zhang, Y., He, Z. H., Xu, S. C., Singh, R. P., Qu, Y. Y., and Xia, X. C. 2006. Molecular mapping of stripe rust resistance gene $\mathrm{YrCH} 42$ in Chinese wheat cultivar Chuanmai 42 and its allelism with $Y r 24$ and $Y r 26$. Theor. Appl. Genet. 112:1434-1440.

18. Li, Q., Chen, X. M., Wang, M. N., and Jing, J. X. 2011. Yr45, a new wheat gene for stripe rust resistance on the long arm of chromosome 3D. Theor Appl. Genet. 122:189-197.

19. Li, Z. F., Zheng, T. C., He, Z. H., Li, G. Q., Xu, S. C., Li, X. P., Yang, G. Y. Singh, R. P., and Xia, X. C. 2006. Molecular tagging of stripe rust resistance gene YrZH84 in Chinese wheat line Zhou 8425B. Theor. Appl. Genet. 112:1098-1103.

20. Li, Z. Q., and Zeng, S. M. 2002. Pages 41-50 and 164-173 in: Wheat Rust in China. Chinese Agricultural Press, Beijing.

21. Line, R. F. 2002. Stripe rust of wheat and barley in North America: a retrospective historical review. Annu. Rev. Phytopathol. 40:75-118.

22. Liu, X. K. 1988. A preliminary study on the inheritance of resistance to stripe rust in wheat. Acta Phytophylac. Sin. 15:33-39.

23. Lu, Y. M., Lan, C. X., Liang, S. S., Zhou, X. C., Liu, D., Zhou, G., Lu, Q. L., Jing, J. X., Wang, M. N., Xia, X. C., and He, Z. H. 2009. QTL mapping for adult-plant resistance to stripe rust in Italian common wheat cultivars Libellula and Strampelli. Theor. Appl. Genet. 119:1349-1359.

24. Mallard, S., Gaudet, D., Aldeia, A., Abelard, C., Besnard, A. L., Sourdille, P., and Dedryver, F. 2005. Genetic analysis of durable resistance to yellow rust in bread wheat. Theor. Appl. Genet. 110:1401-1409.

25. Maniatis, T. A., Frisch, E. F., and Sambrook, J. 1982. Pages 514-517 in: Molecular Cloning: A Laboratory Manual. Cold Spring Harbor Laboratory Press, Cold Spring Harbor, NY.

26. McIntosh, R. A., Devos, K. M., Dubcovsky, J., Rogers, W. J., Morris, C. F., Appels, R., Somers, D. J., and Anderson, O. A. 2007. Catalogue of gene symbol for wheat: 2007 supplement. http://wheat.pw.usda.gov/ggpages/ awn/53/Textfiles /WGC.html

27. McIntosh, R. A., Dubcovsky, J., Rogers, W. J., Morris, C., Appels, R., and Xia, X. C. 2009. Catalogue of gene symbols for wheat: 2009 supplement http://www.shigen.nig.ac.jp/wheat/komugi/genes/macgene/supplement2009.pdf

28. McIntosh, R. A., Wellings, C. R., and Parker. 1995. Pages 1-12 in: Wheat Rust: An Atlas of Resistance Genes. CSIRO Publications, East Melbourne, Victoria, Australia.

29. Michelmore, R. I., Paran, R., and Kesseli, R. V. 1991. Identification of markers closely linked to disease-resistance genes by bulked segregant analysis: a rapid method to detect markers in specific genomic regions by using segregating populations. Proc. Natl. Acad. Sci. USA 88:9828-9832.

30. Saghai-Maroof, M. A., Soliman, K., Jorgensen, R. A., and Allard, R. W. 1984. Ribosomal DNA spacer-length polymorphisms in barley: Mendelian inheritance, chromosomal location, and population dynamics. Proc. Natl. Acad. Sci. USA 81:8014-8018.

31. Stubbs, R. W. 1985. Stripe rust. Pages 61-101 in: The Cereal Rusts, Vol II A. P. Roelfs and W. R. Bushnell, eds. Academic Press, New York.

32. Stubbs, R. W. 1988. Pathogenicity analysis of yellow (stripe) rust of wheat and its significance in a global context. Pages 23-28 in: Breeding Strategies for Resistance to the Rusts of Wheat. N. W. Simmonds and S. Rajaram, eds. 
CIMMYT, Mexico, D.F

33. Sun, S. C., Zhao, H. S., Yang, Y. F., Zhang, Q. F., Xue, X. Z., and Zhou, G. H.1990. Studies on selection breeding and utilization of Zhong 4, Zhong 5 as new resistance sources to wheat yellow dwarf virus. Acta Agric. Boreali Sin. 5:78-85.

34. Wan, A. M., Zhao, Z. H., Chen, X. M., He, Z. H., Jin, S. L. Jia, Q. Z., Yao, G., Yang, J. X., Wang, B. T., Li, G. B., Bi, Y. Q., and Yuan, Z. Y. 2004. Wheat stripe rust epidemic and virulence of Puccinia striiformis f. sp. tritici in China in 2002. Plant Dis. 88:896-904.

35. Wang, H. G., Liu, S. B., Li, X. F., Gao J. R., Feng, D. S., and Chen, D. H. 2006. Breeding and identification of six Octoploid Trititrigia. J. Triticeae Crops 26:6-10.

36. Wu, L. R., Yang, H. A., Yuan, W. H., Song, W. Z., Yang, J. X., Li, Y. F., and Bi, Y. Q. 1993. On the physiological specialization of stripe rust of wheat in
China during 1985-1990. Acta Phytopathol. Sin. 23:269-274.

37. Yan, G. P., Chen, X. M., Line, R. F., and Wellings, C. R. 2003. Resistance gene analog polymorphism markers co-segregating with the $\operatorname{Yr} 5$ gene for resistance to wheat stripe rust. Theor. Appl. Genet. 106:636-643.

38. Yang, Z. M., Xie, C. J., and Sun, Q. X. 2003. Situation of the sources of stripe rust resistance of wheat in the post-CY32 era in China. Acta Agron. Sin. 29:161-168.

39. Zhang, Q. Q., Zhang, L. Y., Zhu, W.H., and Xie, S. X. 1998. Utilization of Haynaldia villosa (L.) Shur in resistance breeding in wheat. Acta Phytophylac. Sin. 25:41-45.

40. Zhou, Y. C., Zhang, X. Q., Wang, X. P., Wu, L. R., Zhou, W. J., Zhang, W. J., and Jing, J. K. 2001. Chromosomal location and molecular marker of resistance gene to Puccinia striiformis West. in Leymus mollis Trin. Hara. Acta Genet. Sin. 28:864-869. 